\title{
The application of time-series MODIS NDVI profiles for the acquisition of crop information across Afghanistan
}

\author{
Daniel M. Simms, Toby W. Waine, John C. Taylor, Graham R. Juniper \\ Cranfield University, Bedfordshire, MK43 OAL, United Kingdom
}

\begin{abstract}
We investigated and developed a prototype crop information system integrating $250 \mathrm{~m}$ MODIS Normalised Difference Vegetation Index (NDVI) data with other available remotely sensed imagery, field data and knowledge as part of a wider project monitoring opium and cereal crops. NDVI profiles exhibited large geographical variations in timing, height, shape and number of peaks with characteristics determined by underlying crop mixes, growth cycles and agricultural practices. MODIS pixels were typically bigger than the field sizes but profiles were indicators of crop phenology as the growth stages of the main first-cycle crops (opium poppy and cereals) were in phase. Profiles were used to investigate crop rotations, areas of newly exploited agriculture, localised variation in land management and environmental factors such as water availability and disease. Near-real time tracking of the current year's profile provided forecasts of crop growth stages, early warning of drought and mapping of affected areas. Derived data-products and bulletins provided timely crop information to the UK Government and other international stakeholders to assist the development of counter-narcotic policy, plan activity and measure progress. Results show the potential for transferring these techniques to other agricultural systems.
\end{abstract}

\section{Introduction}

This work investigates the use of MODIS data as part of a prototype information system to improve understanding of Afghan agriculture and crop production. The approach was to integrate $250 \mathrm{~m}$ Normalised Difference Vegetation Index (NDVI) from MODIS with other available sources of remotely sensed imagery, field data and knowledge to investigate the contribution it could make to timely generation of crop information and if appropriate to make operational use of it. Of particular interest was: increased and more spatially complete understanding of the agricultural systems in Afghanistan; determination and forecast of crop development cycles for crop surveys and poppy eradication activities; and investigation of water availability and disease influences on crop production.

The work was motivated by the need for improved information on opium poppy and cereal cultivation in Afghanistan and was part of a major project sponsored by the UK government. This wider investigation, explained in Taylor et al. (2010), evolved from methodology trials in 2003 into an independent survey for the main opium cultivating provinces from 2005. At its peak in 2007 the survey covered 1.2 million ha of agricultural land and $90 \%$ of the total opium cultivation in Afghanistan, the World's major producer of illicit opium. The results were used by US, UK and the UN to inform international counter-narcotic policy, plan actions and measure progress with the policy objectives.

In Afghanistan, there is great variation in timing and productivity of crops and a lack of reliable crop information, due in part to the country's size, varied topography, poor infrastructure and the loss of institutional knowledge after years of political instability. It is also difficult to collect field information on crops through the growing season because of poor security in the opium producing provinces, therefore such information is sparse and often non-existent, particularly in remote areas.

Remote sensing of annual and inter-annual vegetation development requires high frequency collections to allow enough cloud-free images to reconstruct the diagnostic shape of the growth curve. Wide-area coverage is also required for capturing large geographical areas in single dated scenes with minimal atmospheric and land surface differences. In 
time-series analysis, this maximises data available for each date and reduces further processing due to image mosaicking of smaller individual scenes. Remote sensing imagery that satisfies these requirements has a coarse spatial resolution, where pixels may contain sub-pixel mixtures of the crop types under investigation. Because of this, coarse level data are often used for monitoring natural systems or generic land-cover classes rather than spatially complex agricultural systems (Wardlow and Egbert, 2008).

Numerous previous studies have shown the advantages of using coarse resolution (1 $\mathrm{km}$ ) satellite imagery from the Advanced Very High Resolution Radiometer (AVHRR), with its large area coverage and high collection frequency, for vegetation monitoring and agricultural information. Examples are for the study of the phenology of global vegetation (Justice et al., 1985), wildlife management and food security assessment in Southern Africa (Sannier et al., 1998), and monitoring vegetation biomass for fire risk assessment in Nambia (Sannier et al., 2002). These use NDVI described by Tucker (1979), which provides a measure of photosynthetically active vegetation. NDVI is calculated from the near-infrared and red image bands using the equation

$$
N D V I=\frac{\rho_{\text {nir }}-\rho_{\text {red }}}{\rho_{\text {nir }}+\rho_{\text {red }}}
$$

where $\rho_{\text {nir }}$ and $\rho_{\text {red }}$ are the near-infrared and red reflectance respectively. The success of research into the relationship between spectral index measurements, such as NDVI, and vegetation biophysical properties has encouraged the use of satellite observations for measuring changes in vegetation production (Goward et al., 1991).

Since 2000, the Moderate Resolution Imaging Spectroradiometer (MODIS) on-board NASA's Terra and Aqua satellites has been used for vegetation studies over wide areas with improved spatial resolution. MODIS is ideally suited to monitoring temporal changes in NDVI, collecting daily global imagery in the red $(620-670 \mathrm{~nm})$ and nearinfrared (841-876 nm) wave bands at a resolution of $250 \mathrm{~m}$. Time-series MODIS has been used for calculation of vegetation green-up date (Wardlow et al., 2006) and profiling in the central US (Wardlow and Egbert, 2008), and the classification of agricultural areas from surrounding forest and savannah in Brazil (Victoria et al., 2012). These studies investigated agricultural systems where the field sizes are much larger than the $250 \mathrm{~m}$ nominal pixel size of MODIS, allowing growth cycles to be extracted for individual crops. Unlike these previous studies, the common field sizes in Afghanistan are much smaller ( $<1 \mathrm{ha})$, with single MODIS pixels containing the integrated response from multiple fields. The sensitivity of MODIS NDVI time-series to phenological changes for complex agricultural systems at this scale is currently unexplored.

The aim was to investigate MODIS NDVI profiles for extracting timely and practical crop information in the Afghan context. The research approach was the systematic detailed comparison of NDVI profiles with reference information to identify and understand the crop information contained in profile features. The research questions were: (1) do variations in the NDVI profile reflect distinct crop growth stages of individual crops at the $250 \mathrm{~m}$ resolution of MODIS; (2) can variations in crop phenology across the growing areas be identified; (3) are patterns such as multiple yearly cycles, crop rotations and fallow periods discernible from the profiles; and (4) what level of spatial detail can be detected?

\section{MODIS NDVI profiles}

MODIS Terra MOD02QKM image products were downloaded for Afghanistan from NASA's Distributed Active Archive Center (DAAC) via the Level 1 and Atmosphere Archive and 


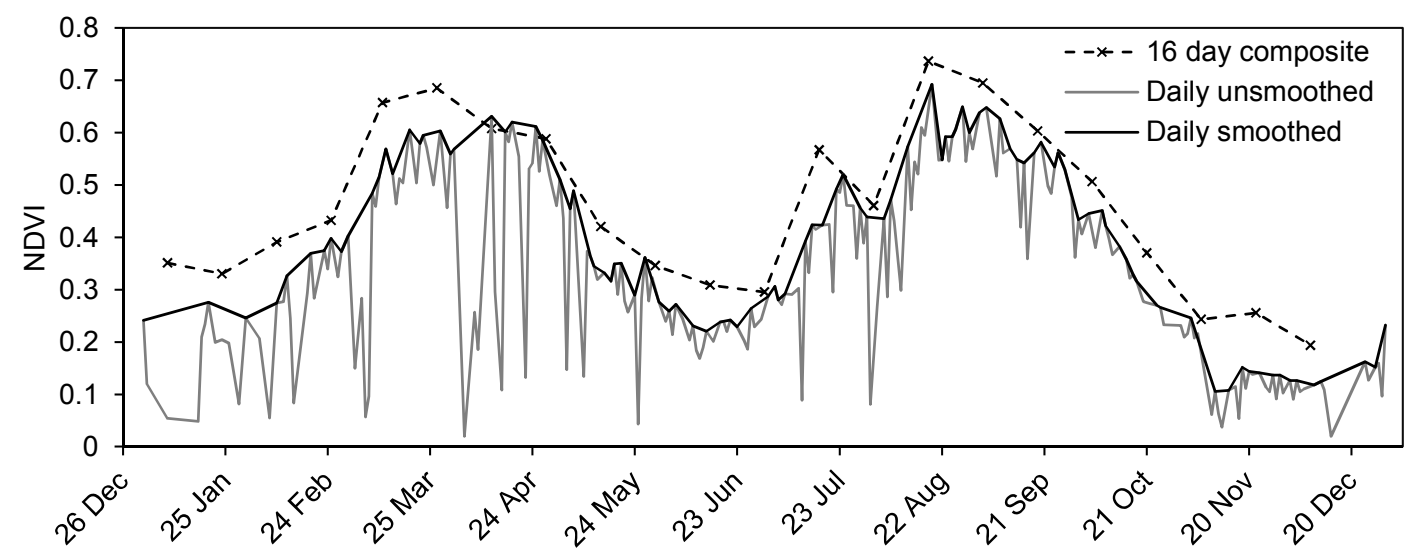

Figure 1: Comparison of MODIS NDVI 16-day composite (MOD13Q1) with smoothed and un-smoothed NDVI calculated from MODIS daily reflectance (MOD02QKM).

Distribution System (LAADS) website starting from February 2000. The criteria for image selection were: near nadir images; predominantly cloud free; and whole country coverage in a single image. Nadir images have minimum distortion resulting from the viewing angle of the sensor. Because of problems in obtaining cloud free images across the whole country some partially cloudy (up to $25 \%$ cloud), off-nadir and partial country coverage scenes were included. Cloud cover was of greater concern during the November-April periods, especially in the mountainous areas of Afghanistan. Selected images were processed using the NASA supplied MODIS Swath Reprojection Tool (MRT Swath) and MOD03 geolocation product to achieve the sub-pixel accuracy necessary for timeseries monitoring (Wolfe et al., 2002). An NDVI image was produced for each reflectance calibrated MODIS image and added in chronological order into a yearly stack. The date of image acquisition was linked to the stack-image band index using a separate database table. An automatic processing chain was developed for updating the NDVI stacks from downloaded MODIS images to provide profiles in near-real time.

Factors unrelated to the vegetation response can account for significant noise in the extracted profile. These variations can be attributed to sensor calibration, atmospheric conditions and the viewing angle (Goward et al., 1991). To improve profile interpretability, a smoothing algorithm was applied to the extracted data to remove changes in NDVI that are not related to the growth of the crop. The approach was modified from Viovy et al. (1992) and uses a moving, forward looking time window to remove high frequency variation and random changes caused by data errors such as saturated pixels.

Another approach to removing noise in NDVI profiles is to use composite data. MODIS 16-day composite products (MOD13Q1) are available for download that contain a representative NDVI value for the composite period; selected by filtering the data based on the quality, presence of cloud and viewing angle of the sensor (Huete et al., 2002). Figure 1 shows a comparison of the 16-day composite product (MOD13Q1) with daily smoothed and unsmoothed NDVI calculated from MOD02QKM daily reflectance. The composite data show a similar shape to the smoothed daily values with greater temporal stability. The systematic offset in the composite values is attributed to the preferential selection of the highest NDVI values within the compositing period (Hmimina et al., 2013) and the increase in NDVI values due to the atmospheric correction applied during generation of the MOD13Q1 product (van Leeuwen et al., 2006).

The generalisation of the NDVI values for the composite profile masks some of the 
variation that could be related to phenological changes. Plotting values at the median date of the compositing period will also lead to a shift from the actual collection date of the NDVI value. With the flowering period of poppy lasting only two weeks, the timing shift in the profile could have a significant effect on the sensitivity and operational use of the profile information. Since the research was focused on detailed analysis at the limit of MODIS resolution, the use of daily NDVI values were preferred to composite data because of the potential loss of diagnostic detail in the profile shape and timing. The time delay between imagery collection and availability of 16-day composite products (3-4 days after the compositing period) also limited their use for near-real time monitoring.

To aid the analysis, an interactive tool was developed within a GIS for generating profiles by querying locations in the context of the reference spatial datasets. The tool was designed to display profiles for any location in Afghanistan with users able to modify the date range of extracted profiles and control the amount of smoothing. Profiles were extracted for single pixels and $3 \times 3$ pixel averages to assess the effect of local smoothing on profile interpretation.

\section{Availability and preparation of reference data}

Direct access to the field for the collection of ground data for cross-referencing with MODIS NDVI profiles was not possible because of security threats. In the early stages of the research, crop data were made available by the United Nations Office on Drugs and Crime (UNODC) through our role as formal advisors on the development of survey design, survey methodology and image analysis. For its yearly cultivation survey the UNODC collects a sample of very high resolution (VHR) satellite images (sample blocks) distributed across Afghanistan, and ground data $(250 \times 250 \mathrm{~m}$ segments $)$ within the imaged area. Segments are visited by UNODC trained surveyors and the crop types within individual fields are identified and photographed (UNODC, 2005). Ground observations of crop types and geo-referenced photography is also collected during field visits by UNODC surveyors at locations away from the image blocks.

As the project evolved into an independent survey, further VHR (IKONOS and Quickbird) images were added to the database each year together with full coverage multispectral medium-resolution imagery ( 32 and $22 \mathrm{~m}$ ) from the Disaster Monitoring Constellation (DMC) satellites. In 2007, aerial digital photography (ADP) was collected in 21 provinces at multiple dates for image-interpretation of poppy at sample locations and verification of claimed eradication. Geo-referenced ground photography from multiple sources, including the UNODC cultivation and eradication verification surveys, for each year were also added to the database.

Meticulous orthorectification of all imagery datasets was undertaken to ensure the accurate co-registration with extracted MODIS NDVI profiles. This was carried out by the project team as the geometric accuracy of the products from imagery suppliers were not sufficiently accurate. Processing in-house also reduced image delivery time and allowed full quality control of the image correction process. All datasets were ortho-rectified using a country-wide $30 \mathrm{~m}$ digital elevation model (DEM) and a controlled image base (CIB) for control. Quickbird and IKONOS scenes were ortho-resampled using a version of the vendor supplied Rational Polynomial Camera model refined using ground control (Grodecki and Dial, 2001). ADP was orthorectified using standard photogrammetric techniques to refine the initial stereo model derived from the aircraft's inertial measurement unit (IMU). Each block of overlapping frames was triangulated by bundle adjustment of automatically generated tie points. The resulting models were improved and quality checked 
using horizontal ground control from the CIB. Frames were then ortho-resampled using a DEM extracted from the stereo model of the block. Check point residuals of $<5 \mathrm{~m}$ were achieved for VHR image and ADP ortho-rectification. Sub-pixel rectification of the DMC imagery was achieved using ground control and a rigorous sensor model developed by Spacemetric AB, available within Keystone Workstation software.

Field observations and photography were quality checked by plotting their coordinates on the ortho-rectified VHR imagery. By identifying features visible in the photographs on the VHR imagery it was possible to detect, and is some cases correct, errors in the geolocation of photos and shifts in the location of field observations.

Between 2005-2009 over 300 VHR scenes, 33 DMC images (full-country coverage between 2007-2009) and 12,500 frames of ADP were collected across the major poppy cultivating provinces. Figure 2 shows the spatial distribution of the imagery datasets together with the UNODC field segments and photography locations for 2005. This large reference database allowed for extensive cross-referencing to analyse and verify the consistency of MODIS NDVI profile interpretation.

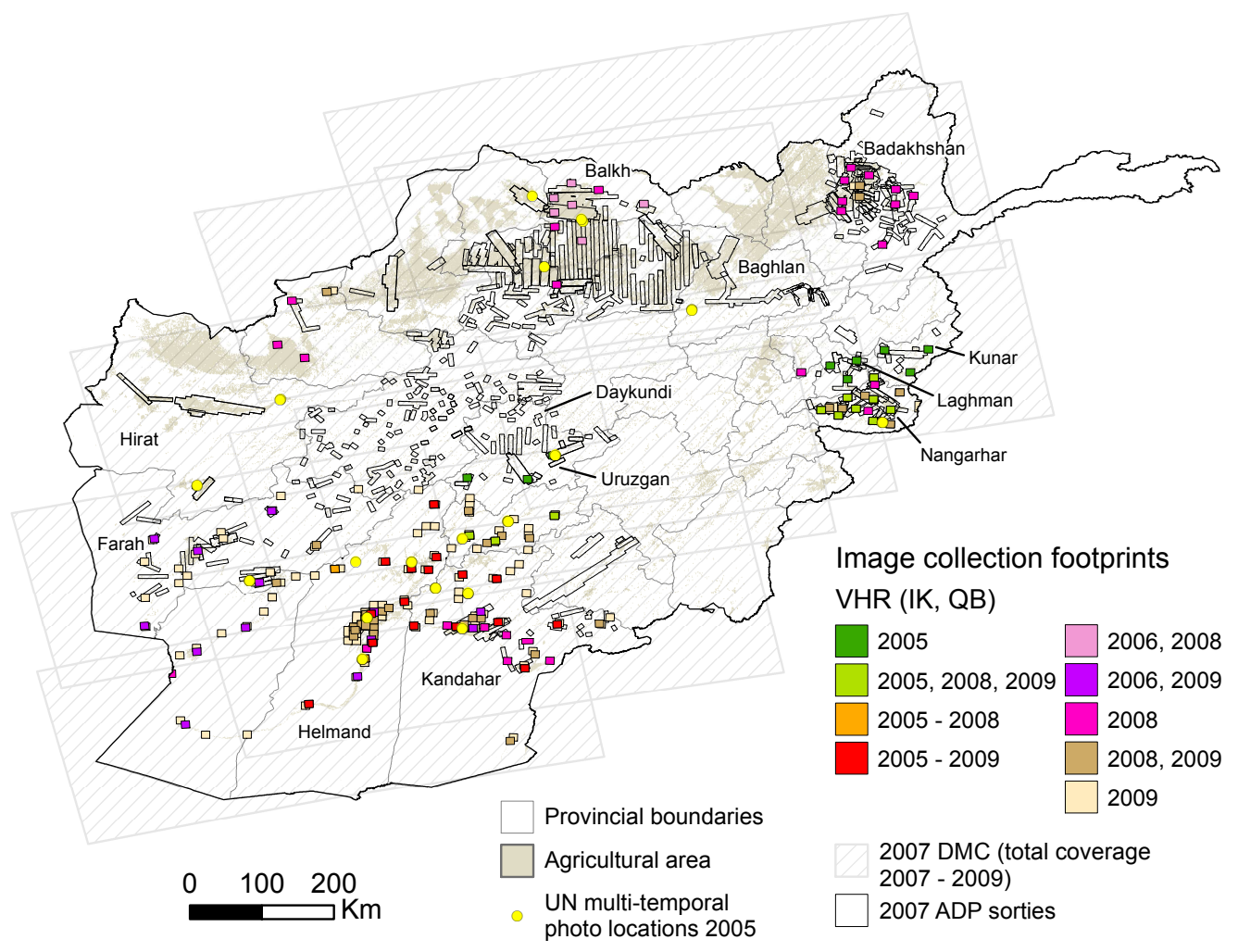

Figure 2: Distribution of very high resolution (VHR), medium resolution DMC and aerial digital photography (ADP) collections between 2005-2009 in the main opium producing provinces of Afghanistan.

\section{Profile interpretation}

\subsection{Temporal cropping patterns}

The seasonal development of profiles was compared at numerous locations identified from the reference datasets in areas of opium production. These included rain-fed (dryland) and irrigated sites in the main agricultural areas and upland valleys. 


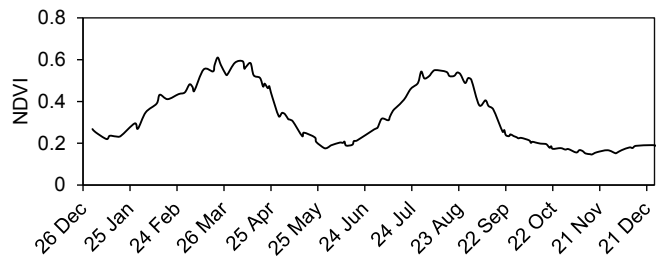

(a) Two distinct cycles

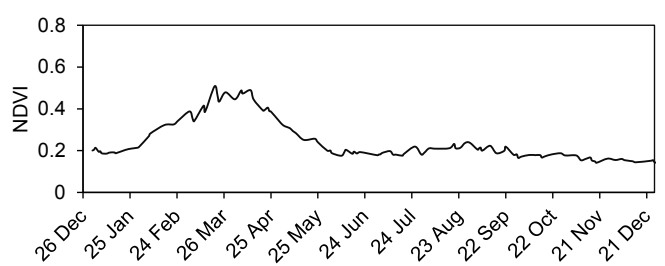

(c) Single cycle

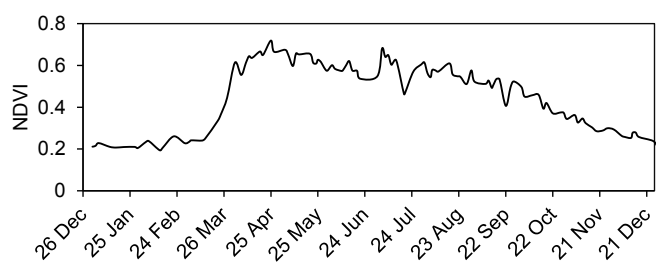

(e) Tree crops

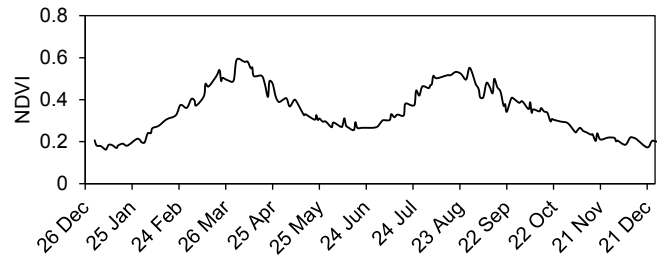

(b) Two overlapping cycles

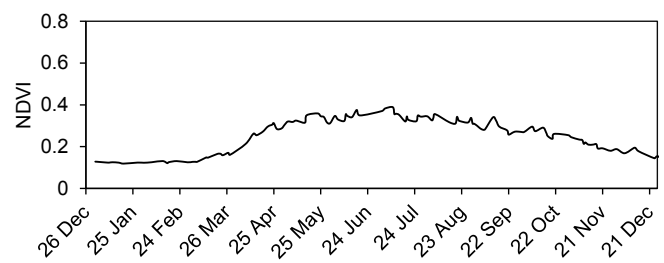

(d) Vines

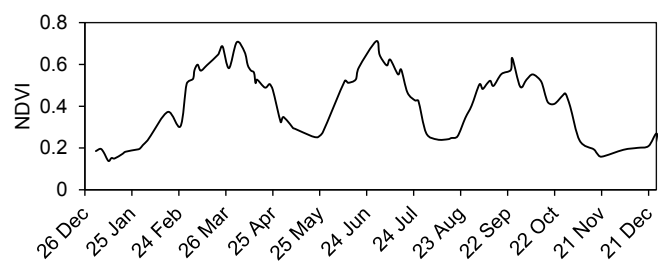

(f) Three distinct cycles

Figure 3: Examples of multi-temporal cropping patterns identified from MODIS NDVI profiles across the opium producing provinces of Afghanistan.

Figure 3 shows examples of distinct temporal cropping patterns identified from analysis of the profile shapes. Figure 3(a) shows double peaks representing separate crop cycles, where the NDVI value returns to the baseline between peaks. Double peaked profiles were also identified containing overlapping first and second cycle crops planted in the same crop-mix (figure 3(b)). Opium poppy and cereal crops such as wheat, barley and oats are typical first cycle crops. Second cycle crops include vegetables and maize. Poppy is not grown in the second crop cycle as it is not suited to the heat of late summer.

Higher altitude locations (greater than $1500 \mathrm{~m}$ ) tend to have single crop cycles (figure 3(c)) as there is limited growing time between snow melt in March-April and the onset of winter. Distinctive single profiles with a more gradual return to the baseline were identified in crop-mixes dominated by vines (figure 3(d)) and tree crops (figure 3(e)); with tree crops distinguished by a steeper green-up and higher peak due to their increased canopy biomass compared to vines. A small area in central Nangarhar Province was identified with three distinct peaks (figure 3(f)) containing short cycle crops.

\subsection{Crop phenology}

NDVI profiles were cross-referenced with field data collected by UNODC in 2005, consisting of multi-temporal crop photography from 47 field locations, which represented the large geographical variation of the poppy growing areas (figure 2). Field data included the main crops grown in the first cycle with opium poppy, namely cereals and the forage crops clover (Trifolium) and alfalfa (Medicago sativa L.). 
Figure 4 shows an example of the profile extracted for the site in Musa Quala, Helmand Province with the dates of the photographs showing the growth stages of the crops. Before February the profile is relatively stable with a low NDVI value of around 0.15 , indicating the presence of limited amounts of photosynthetically active vegetation. The poppy and cereal crops at this location were either autumn sown and remained largely dormant during the winter, or spring sown and emerged late January or early February. Leaf production increases the plants' biomass and starts the upward trend in the profile at (a). By March the biomass has increased (b) as the poppy moves into stem elongation and the wheat into tillering followed by stem elongation. A few weeks later the poppy plants develop buds in a distinctive hook shape and flowering starts in early April at the same time as cereal crop anthesis (flowering) (c). The peak in NDVI indicates the peak green vegetation activity around the end of poppy flowering $(\mathrm{d})$ and the start of seed-capsule development. Reflectance changes in sub-pixel poppy fields due to colour differences at flowering are a small part of the reflected signal at the scale of MODIS and flowering poppy itself was not observed in the profiles. The opium harvest starts once the green poppy capsules have developed, and lasts while the scored capsules still provide opium gum. Once the opium harvest is finished the poppy plants are no longer irrigated and quickly dry and senesce (die back) (e). There is a rapid decline in photosynthetic activity, showing as a decrease in the NDVI profile back to the baseline. The cereal crops are ripening at the same time, in phase with the poppy and are harvested later in June. The dead poppy plants and capsules often remain in the ground (f) and are then cleared (g) in preparation for the next crop.

Alfalfa and other vegetable crops occupied only a small proportion of the cropped area. Alfalfa is typically cut for feeding as green plant material or made into hay, and generally produces multiple cuts each year. Vegetables usually had short growth cycles and were progressively harvested green. This means that the peak vegetation activity of these crops is often out of phase with the predominant cereal and poppy crops. However, at current Afghan production levels the effect was not visible in the overall profile trends.

The peak vegetation activity, corresponding to the first cycle peak of the NDVI profile, was at the flowering stages of both poppy and wheat. The timing of the flowering period is critical information for planning of counter-narcotic and cultivation survey activities and also coincides with the optimum time for image-interpretation of poppy crops in VHR images. The growth stages of the main crops were found to be in phase and profiles were indicative of the phenology of the sub-pixel crop mix. A mixed profile from staggered planting and development dates in multiple sub-pixel crop cycles would limit the use of coarse resolution MODIS. However, this was not observed in the reference data for the main opium producing provinces, where the crop mix is dominated by cereals and poppy.

\subsection{Interpretation of peak NDVI}

The photosynthetic response between years measured by the difference in peak NDVI can be related to changes in productivity where a MODIS pixel is dominated by a single crop (Becker-Reshef et al., 2010). At the field scale in Afghanistan, the peak NDVI is the combined response from sub-pixel field parcels and will vary according to the composition and vigour of the individual crops. The effect of crop mix on profile height was investigated to assess if peak NDVI could be used as an indirect measure of productivity at the resolution of MODIS. All available ground segments and visual interpretations from the reference VHR imagery were compared with NDVI profiles for each year of available data. Profiles were compared at the same locations between years so NDVI measurements were independent of the difference in background soil. Figure 5 shows an example for the 

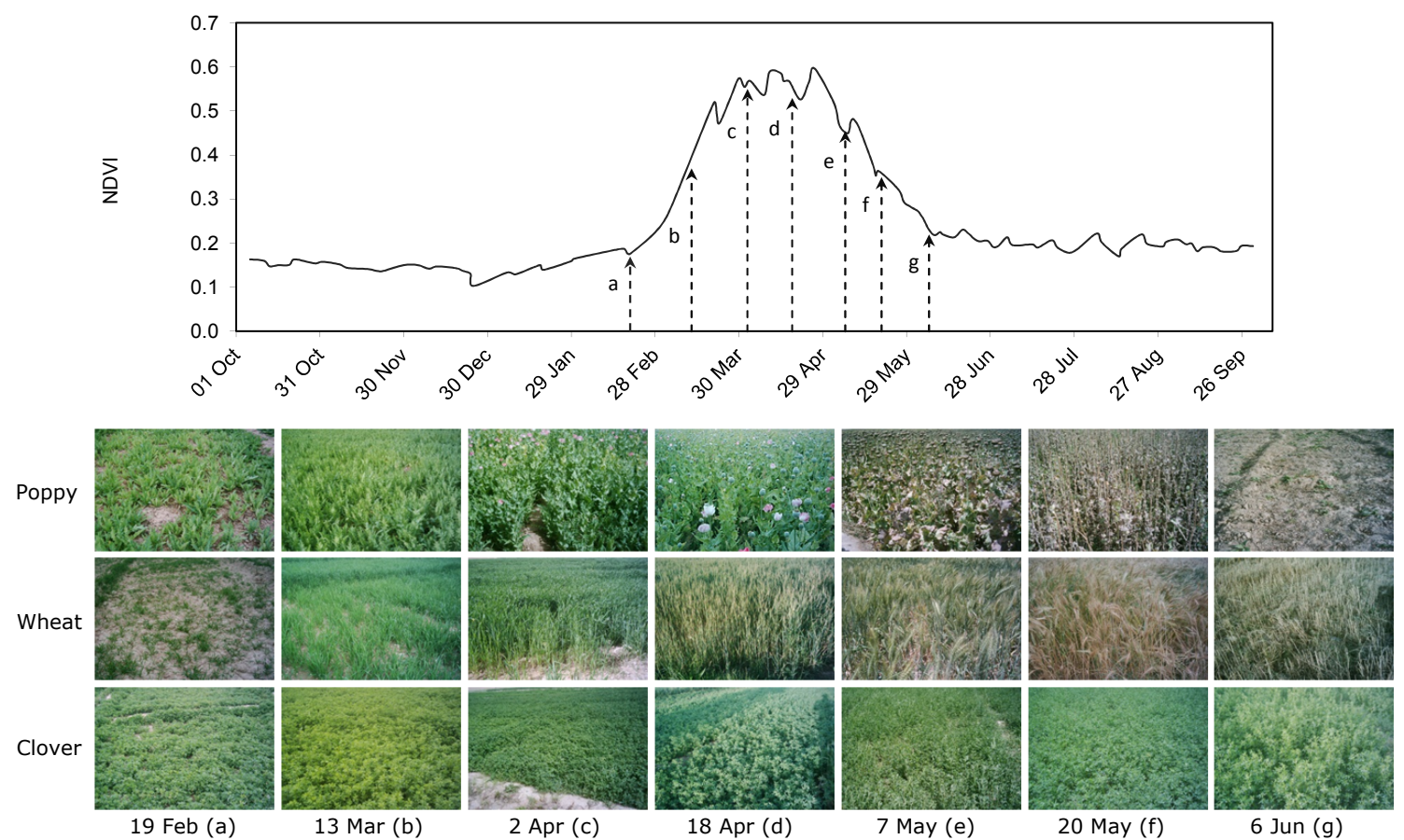

Figure 4: MODIS NDVI profile development in 2005 evidenced by UNODC ground photography for opium poppy, wheat and clover in Musa Qala, Helmand Province. Photography @UNODC/Ministry of Counter Narcotics, Government of Afghanistan.

growing seasons 2005-2007 in Helmand Province. High resolution (1 m natural colour pan-sharpened) VHR IKONOS image subsets of the area around the MODIS pixel (nominal $250 \mathrm{~m}$ pixel location indicated by red square) are shown for each year. The general timing of the subsets and ground photography are marked on the profile $(\mathrm{a}=3 \mathrm{rd}$ week of March; b = 2nd week of April; and c = 3rd week of April). For the 2005 and 2006 season, the peak NDVI values are approximately 0.55. In 2007 the peak NDVI is reduced to 0.3 . The poppy and wheat fields are in rotation between 2005 and 2006 while the vineyards are present in all three years. In 2007 a higher proportion of bare ground in the crop mix within the MODIS pixel is visible which lowers the average NDVI.

The variation in profile height reflected changes in vegetation activity relating to growing conditions and the mix of crop types. In irrigated areas with a stable crop mix, the magnitude of the profile peak was used to compare the relative productivity between years. In marginal areas, variation in profile height was indicative of a change in the number of planted fields resulting from crop rotation, crop failure or farmer decisions not to plant because of limited water availability. Profile data were used to map the spatial variability in relative productivity for investigating the quality of agricultural land and the effects of environmental factors such as cold weather on the development of crops.

\section{Crop information system}

\subsection{Geographical variation in crop timing and planning VHR imagery acquisition}

The survey methodology for estimating the annual area of poppy cultivation relied on image-interpretation of opium crops at sample sites. Accurate interpretation of crops from VHR imagery is affected by the growth stage of the crop at the time of image col- 

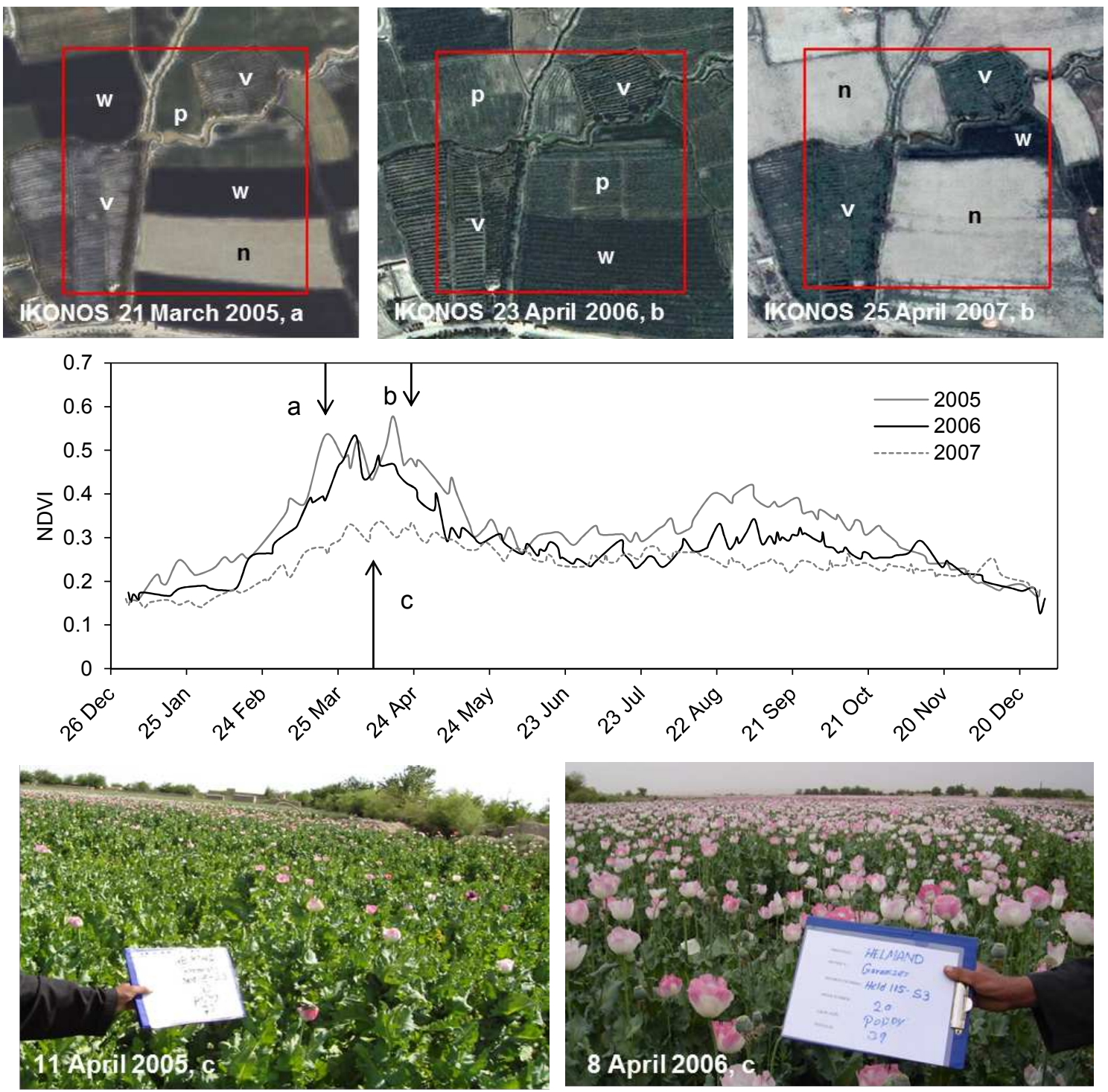

Figure 5: Visual comparison of crop-mix interpreted from VHR IKONOS imagery, ground photography and MODIS NDVI profiles for a location in southern Helmand. Crop types ( $w$ - wheat; $\mathrm{p}$ - opium poppy; $\mathrm{n}$ - no-crop; and v - vines) are identified on the true-colour composite IKONOS subsets with image and photography dates marked on the profile ( $\mathrm{a}$ - 3rd week of March; b - 2nd week of April; and c - 3rd week of April). Photography (OUNODC/Ministry of Counter Narcotics, Government of Afghanistan. 
lection, which is optimal around the flowering period (Taylor et al., 2010) when poppy exhibits a contrasting colour and texture to other crop types. Interpretation becomes uncertain in images collected outside this period, either before the establishment of the crop canopy or after flowering as the crops begin to senesce.

Variations in the timing of the first cycle profile peak were compared at all ground locations in the reference database to assess differences in crop timing across the poppy growing regions. Figure 6 shows an example of crop cycle timing for locations in Helmand (lat. $31.55^{\circ} \mathrm{N}$, alt. $758 \mathrm{~m}$ ), Balkh (lat. $35.81^{\circ} \mathrm{N}$, alt. $1405 \mathrm{~m}$ ) and Badakhshan (lat. $36.61^{\circ} \mathrm{N}$, alt. $2562 \mathrm{~m}$ ). The first cycle peak at the Helmand location is one and three months out of phase with the Balkh and Badakhshan profiles respectively. The profiles are representative of the large variability in phenology caused by latitude and altitude found across Afghanistan.

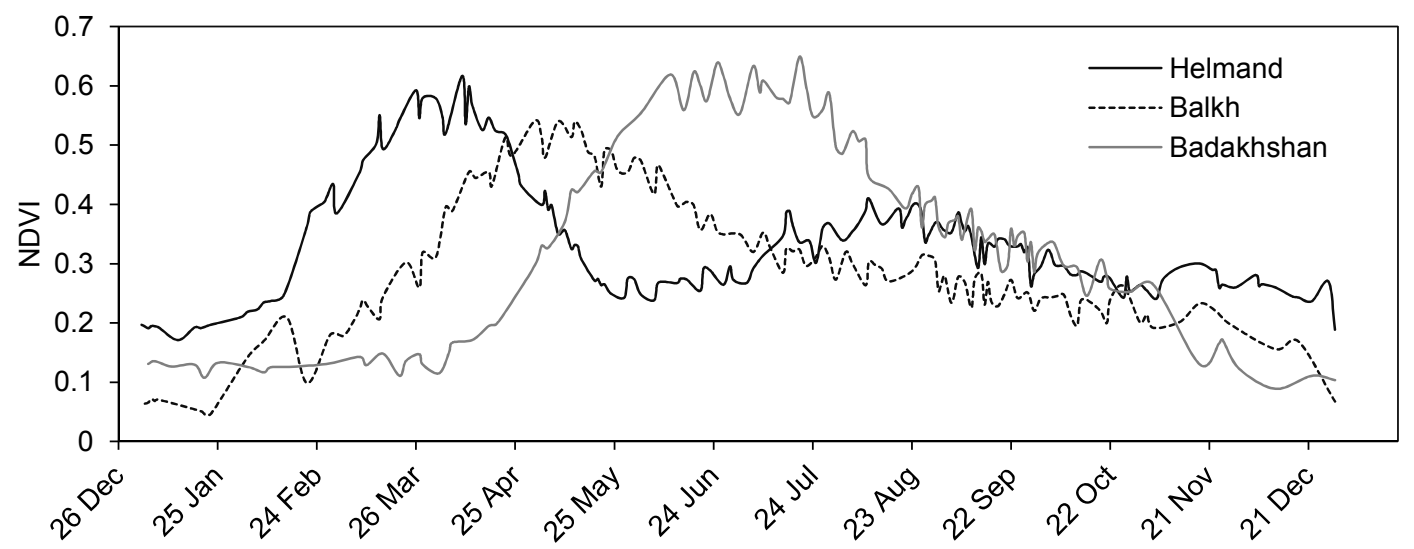

Figure 6: MODIS NDVI profiles at agricultural locations in Helmand (lat. $31.55^{\circ} \mathrm{N}$, alt. $758 \mathrm{~m}$ ), Balkh (lat. $35.81^{\circ} \mathrm{N}$, alt. $1405 \mathrm{~m}$ ) and Badakhshan (lat. $36.61^{\circ} \mathrm{N}$, alt. $2562 \mathrm{~m}$ ) provinces.

Figure 7 shows an example from Badakhshan with a two month timing difference in the first peak between adjacent valleys induced by topographic height differences. This is significant as imagery targeted to coincide with flowering in area (a) will be too early in area (b). Conversely, imagery targeted at (b) will be too late for interpretation in area (a).

By analysing the profiles at individual sample locations, two to three week collection windows were determined for VHR image collections (working back from the peak) and could be adjusted by monitoring the development of the profile in relation to the historical trends. Profiles were also used to define timing zones for poppy flowering over the wider coverage area of the medium resolution (22-30m) DMC imagery.

Establishing the crop development stages and tracking the evolution of the NDVI profiles for the current season in near real time enabled us to create and disseminate forecasts of poppy crop development throughout Afghanistan. In addition, profiles extracted at sample locations after VHR image collection were used to assess the growth stage of crops being interpreted; particularly in cases where images were collected outside of optimum timing windows because of cloud. This enabled analysts to select the appropriate interpretation key for discrimination of the main crops to increase interpretation accuracy, leading to improved area estimates for opium poppy cultivation.

\subsection{Land-use changes and rotations}

The significant yearly variations in the area of agricultural production, mapped by classification of DMC imagery, were identified as potential sources of error in the cultivation 


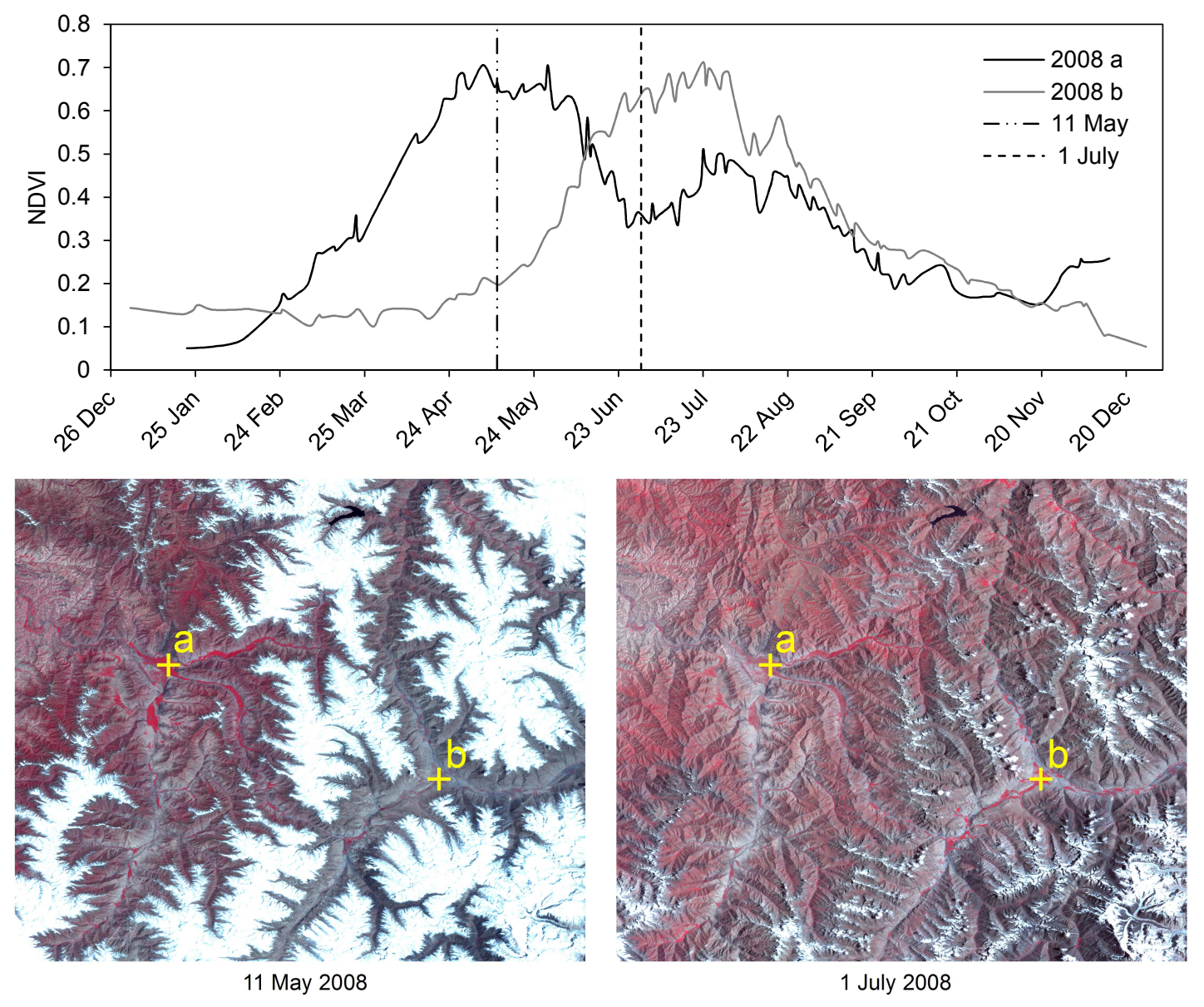

Figure 7: MODIS NDVI profiles extracted for points a and b (70 km apart) in Badakhshan Province shown on DMC false-colour composite image subsets (collection dates marked on the profile).

estimates of opium poppy. These were investigated using profile data to establish if differences were the result of agricultural expansion or part of a system of land rotation. Figure 8 shows two profiles extracted from areas of change in the yearly classification of agricultural land together with near-infrared false-colour multitemporal DMC images, where red indicates the presence of green vegetation. The profile in figure 8(a), extracted from the area of Daman, Kandarhar, shows vegetation activity in alternate years. At this location the imagery clearly shows blocks of agricultural land moving from bare ground into production and back again between 2006-2008. These areas, away from the main irrigated valleys, were part of a managed rotation of agricultural land. Changes in management practices were detectable for areas greater than a MODIS pixel ( $\sim 2 x 2$ pixels) where groups of fields were under similar management. Changes at a finer resolution were not detectable in complex areas as the reflected energy received at the sensor for each MODIS pixel is known to contain a significant amount of signal from the surrounding area (Huang et al., 2002). This increases the NDVI values of non-vegetated areas above the baseline if adjacent pixels contain vegetation.

The profile in figure $8(\mathrm{~b})$ is typical of a newly exploited area with no historical vegetation activity prior to 2007, followed by steadily increasing production. The DMC imagery shows the evolution of the area from desert in 2006 to an established agricultural area with identifiable field structures in 2010. These areas are created to extend the overall cultivated area or to move production of illicit crops away from zones under pressure 


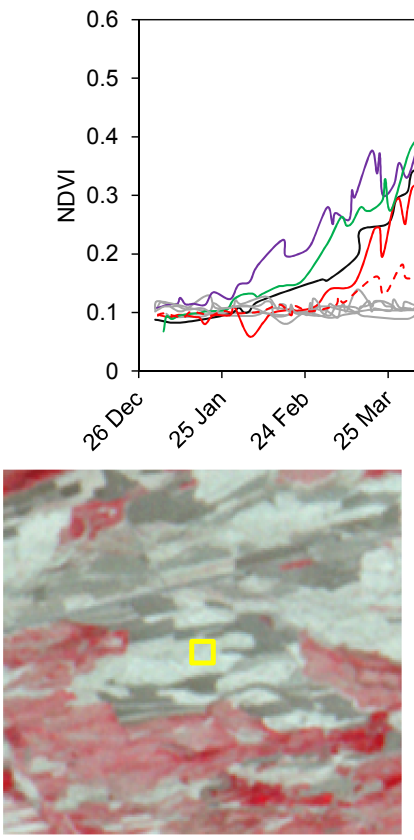

11 April 2006

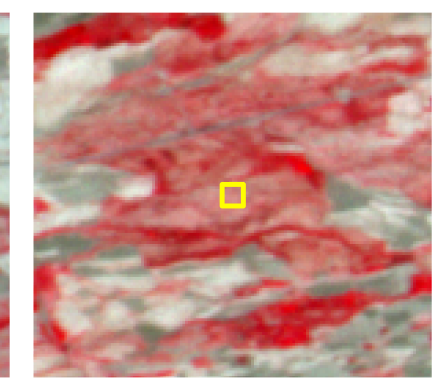

27 April 2007

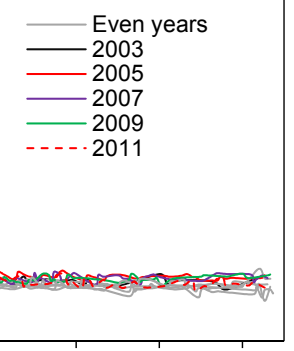

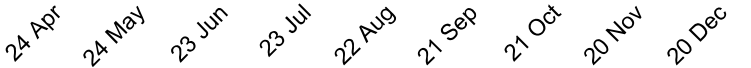

(a)

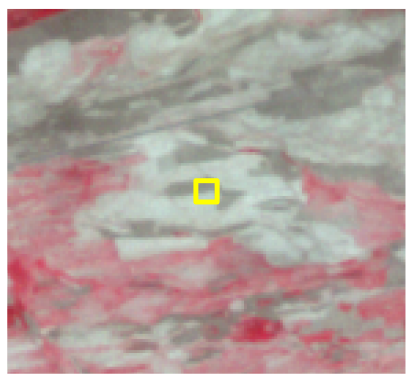

7 April 2008

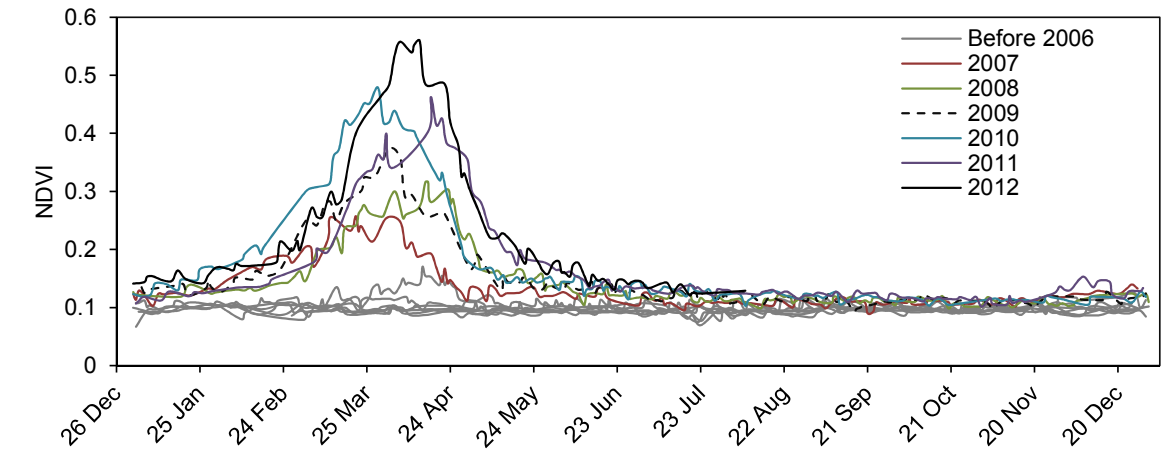

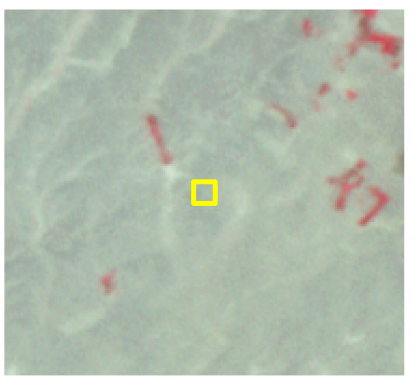

11 April 2006

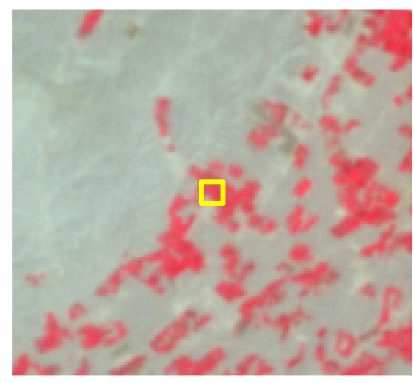

7 April 2008

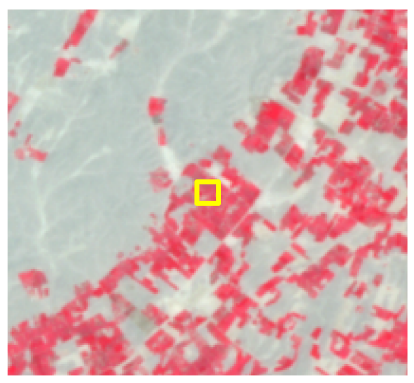

5 April 2010

(b)

Figure 8: MODIS NDVI profiles and multitemporal DMC image subsets (near-infrared false colour composite) for areas of crop rotation(a) in Kandahar province and newly exploited agriculture (b) in Helmand Province. Extraction locations shown by yellow square representing a nominal MODIS pixel $(250 \mathrm{~m} \times 250 \mathrm{~m})$. 
from counter-narcotic activities. New areas of cultivation could be interpreted at a higher resolution (single MODIS pixels) than areas of rotation because of the contrast between new vegetation and the previously bare desert. Profiles were used to verify reports that poppy cultivation had been displaced from the main cultivated area in Helmand Province to the north of the Boghra Irrigation Canal.

Temporal changes in the distribution of agricultural land are significant for assessing the development of newly exploited areas and the year-on-year changes due to environmental factors affecting land management.

\subsection{Verifying field reports of disease}

Figure 9(a) shows a profile for the Kajaki District of northern Helmand for the 2008-2010 growing seasons. The 2010 profile shows an early die-back compared to 2009 data consistent with field reports that fungal disease had resulted in rapid senescence after flowering (D), lowering the yield potential by shortening the harvest period. The 2008 profile shows a delayed green-up in the crops $(\mathrm{F})$ and a reduced peak response caused by the cold spring weather. Fields have reduced biomass due to the restricted growing season and poor crop establishment leading to bare patches within fields.

Diagnostic features of the 2010 profile in figure 9(a) were mapped by identifying the early die-back associated with the disease. The date difference between the end of the 2010 profile and the average yearly profile in the MODIS time-series database for each pixel was calculated; with the end of the first peak defined as the minimum peak height between the first two cycles or the return to baseline for single cycles. Potential die-back pixels were then classified by thresholding the date difference. The map product in figure 9(b) shows the distribution of potential disease areas in northern Helmand Province. Map products derived from the profile database can be used to estimate the spatial extent of environmental phenomena, identifiable in individual profiles, to target the limited ground resources for measuring their effect on opium production.

\subsection{Local changes in land management}

Figure 10 shows three distinct management zones within a small area of Baghlan Province. Profile (a) shows an area with two crop cycles with a generally higher second cycle. Profile (b) has two cycles of approximately equal height and a shape characteristic of a crop mix containing vines or other permanent crops. Profile (c) characterises a zone with less reliable agriculture, with a single cycle and a large variation in the height of the peak between years with no cultivation in 2008, a drought year. Cross referencing the coarse resolution profile data with VHR imagery showed changes in cultivation practices were detectable between adjacent groups of MODIS pixels. This level of spatial sensitivity in the profile data allowed it to be used in conjunction with other, accurately geo-referenced datasets within the GIS for investigating localised variation in cultivation practices and land management. This enabled analysts to assess the multi-temporal variation observed in single dated observations from VHR interpretations and ground data, going back to the start of the MODIS archive in 2000.

\subsection{Reliability of cropping}

The relative inter-annual productivity is an important metric for assessing the quality of agricultural land. Identifying the areas of high double crop reliability allows policy makers to determine where higher production agricultural areas are located, hence where farmers have the best agricultural potential for alternatives to opium poppy cultivation. 


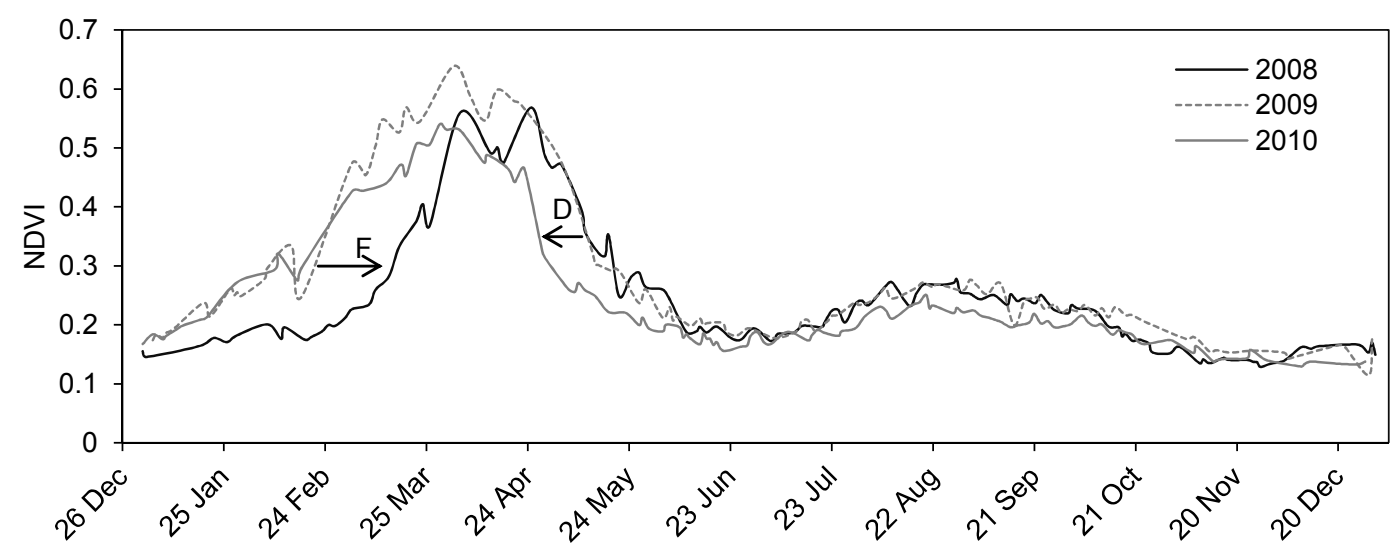

(a)

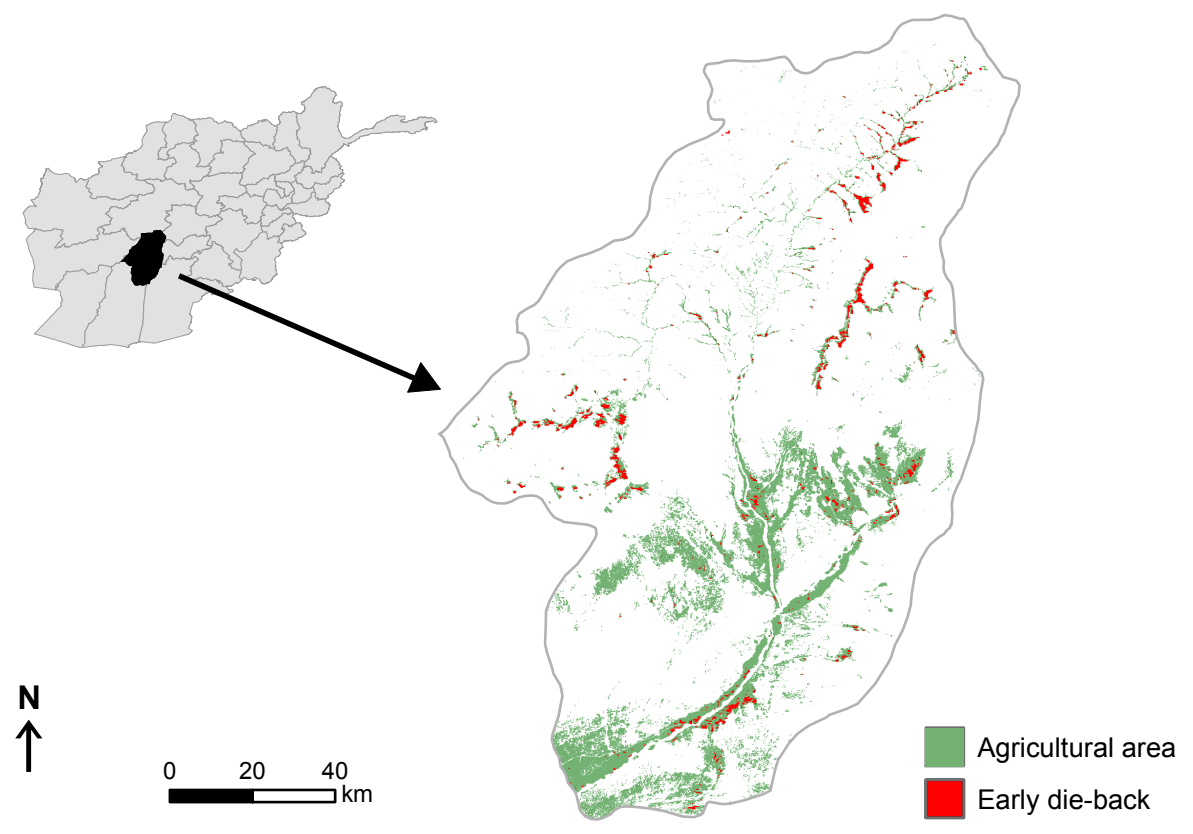

(b)

Figure 9: MODIS NDVI profiles (a) and map of early die-back associated with fungal disease (b) for the north of Helmand Province. Profiles show late green-up in 2008 (F) and early crop senescence in 2010 (D) compared to a typical year (2009). 

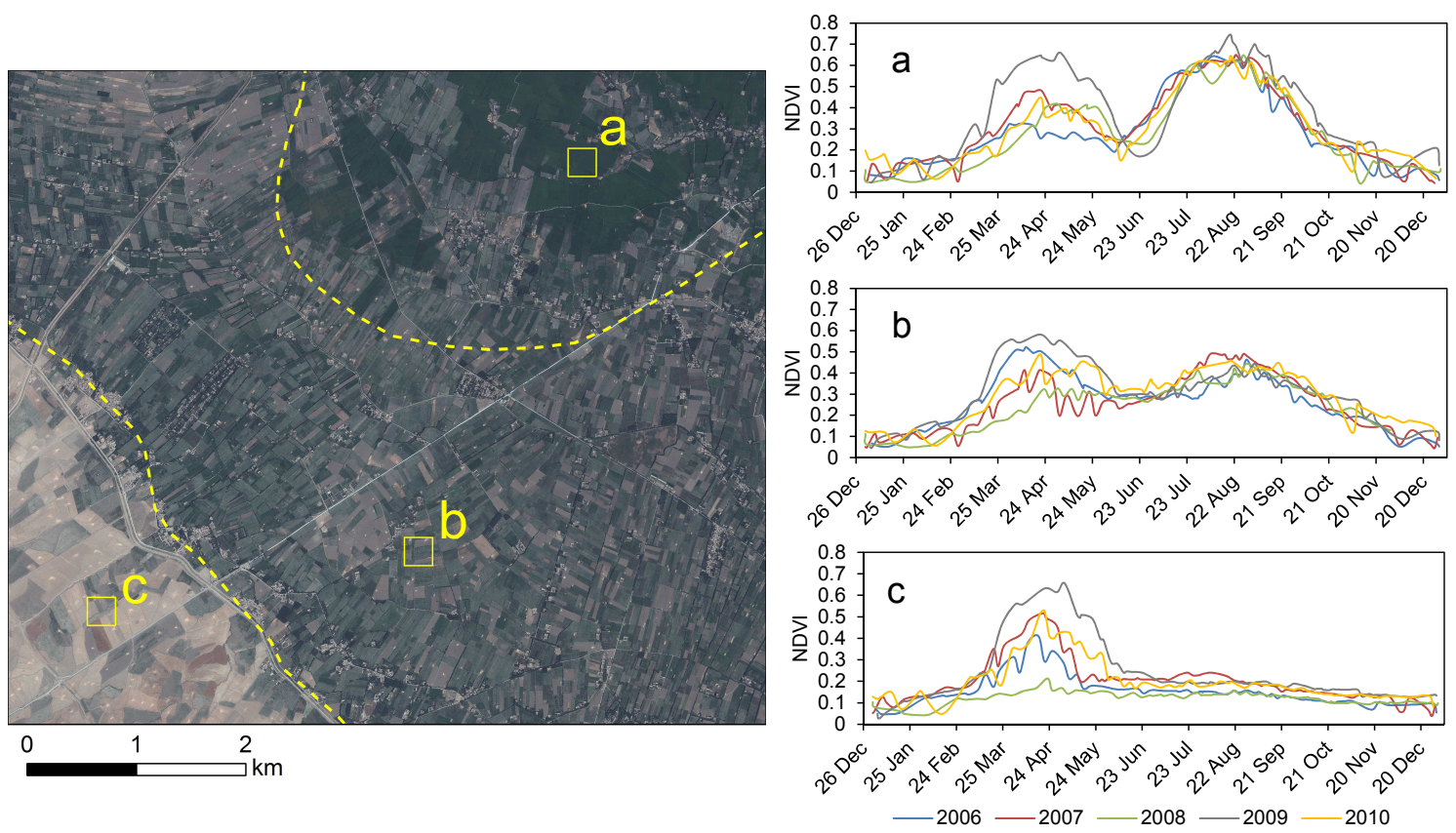

Figure 10: MODIS NDVI profiles for three distinct argricultural zones in Baghlan Province. Zones (separated by dotted yellow lines) and profile extraction locations (nominal $250 \mathrm{~m}$ yellow squares) shown on VHR imagery (GeoEye 13 September 2009).

Figure 11 shows a typical double cropping profile from the main irrigated area of Helmand Province. The profile shows two distinct peaks, the first around the end of March and the second at the end of August, for each year of profile data. Typically such double cropped areas have reliable water supply and operational irrigation systems. At some locations the second crop cycle only occurs in years with sufficient rainfall or snow melt for irrigation.

Map products produced from the geo-database of MODIS NDVI imagery show the historical spatial distribution and reliability of double cropping areas across the whole of Afghanistan. The number of yearly crop cycles was calculated for each MODIS pixel by first splitting each years' profile in two at Julian day 161, which represents the point of maximum separation between the first and second cycles. The date of maximum NDVI for both halves of the profile was then calculated and thresholded to remove low values. Single, double or no crop cycles were classified for each year of profile data according to the occurrence of peaks in each half of the split. Misclassifications caused by peaks occurring around the split date and at the start of the following years' cycle were filtered by setting a minimum distance between peak dates of 90 days.

Figure 12 shows the reliability of double cropping between 2000 and 2006 for the Eastern Afghanistan province of Nangarhar within the area of agricultural production. The colours show the occurrence (or reliability) of two crop cycles in seven years of data. Brown areas have double cropping for 1 year in 7 through to green, where double crop cycles occur in all seven years. In Nangarhar there are broadly two types of agricultural land: the flat irrigated area around the central Kabul River and the snow and rain fed valleys extending northeast from the Safed Koh mountain range that runs along the southern border. The irrigated central valley around the river is highly reliable for double cropping (shown in green). The higher valleys extending from the Safed Koh are also in green indicating good water supply from reliable snow melt each year. Moving northeast towards the central valley, the reliability of double cropping reduces (shown by the colour 
change from green, progressing to brown). Visual interpretation of the winter snow pack showed a link between snow extent and variability in downstream crop reliability. Timeseries MODIS (near-infrared false-colour images) and NDVI profiles were used to assess changes in snow accumulation between years for identifying potential water availability issues early in the growing season. The link between the extent and condition of the snow pack, and net primary production for irrigated agriculture is an area of ongoing research.

\subsection{Near-real time monitoring}

As well as identifying historical trends in cropping, profiles were used in near-real time for monitoring the vegetation development in the current season. Climatic conditions in Afghanistan are highly variable across the country and from year-to-year. Irrigated areas can suffer shortages of water due to a lack of snowmelt. Drought affected areas are mainly identified anecdotally from field reports and are poorly mapped, with no early warning of water shortages that may impact on the production of both illicit and licit crops. Profiles and their derived mapping products were used to assess the reliability of agricultural production as an indicator of drought by plotting the current year's vegetation development in relation to historical profiles using a method adapted from Sannier et al. (1998). Figure 13 shows the drought status in Nangarhar Province for week 15 in 2009. The drought status in the map is calculated by comparing the NDVI in week 15 to the profile history at each pixel location. The profile at location (a) shows the 2009 profile tracking higher than the historical mean and the maximum observed NDVI at this location (green on the map). Conversely, profile $b$ shows a lower than average NDVI with little or no vegetation activity (red on the map). This near-real time information on the current growing season was provided to policy makers in bulletins focused on the early warning of drought and the spatial extent of the affected areas across Afghanistan.

Areas of dry-land agriculture show significant yearly variations in productivity due to fluctuating water availability from unreliable rainfall. Figure 14(a) shows a typical dryland vegetation profile from the Sholgara District of Balkh Province. There is a single vegetation cycle in 2007 with a peak NDVI of 0.5, while in 2008 there is no vegetation activity. Figure 14(b) shows the spatial distribution of active agricultural land in 2007 and 2008 associated with the fall in vegetation activity for the province. The rain-fed southern half has $46 \%$ more active land in 2007 compared to 2008 . Yearly variations can account for significant differences in cultivation estimates; as the area under cultivation is used to extrapolate sample estimates of opium cultivation to provincial and national levels. Profiles were used to monitor these areas to capture trends in the development of vegetation for the season. Early information on dry-land drought conditions was used to reduce VHR image collections over non-productive areas, increasing resources available for other areas. 


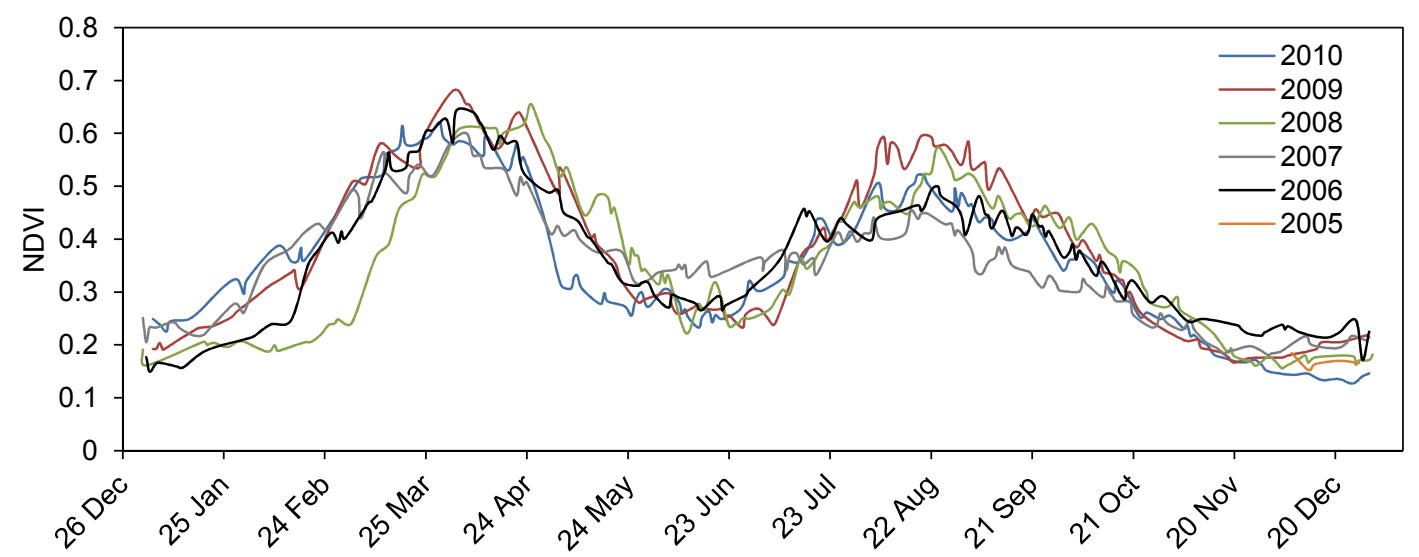

Figure 11: MODIS NDVI profiles for a location in Nad Ali, Helmand Province with reliable double cropping.

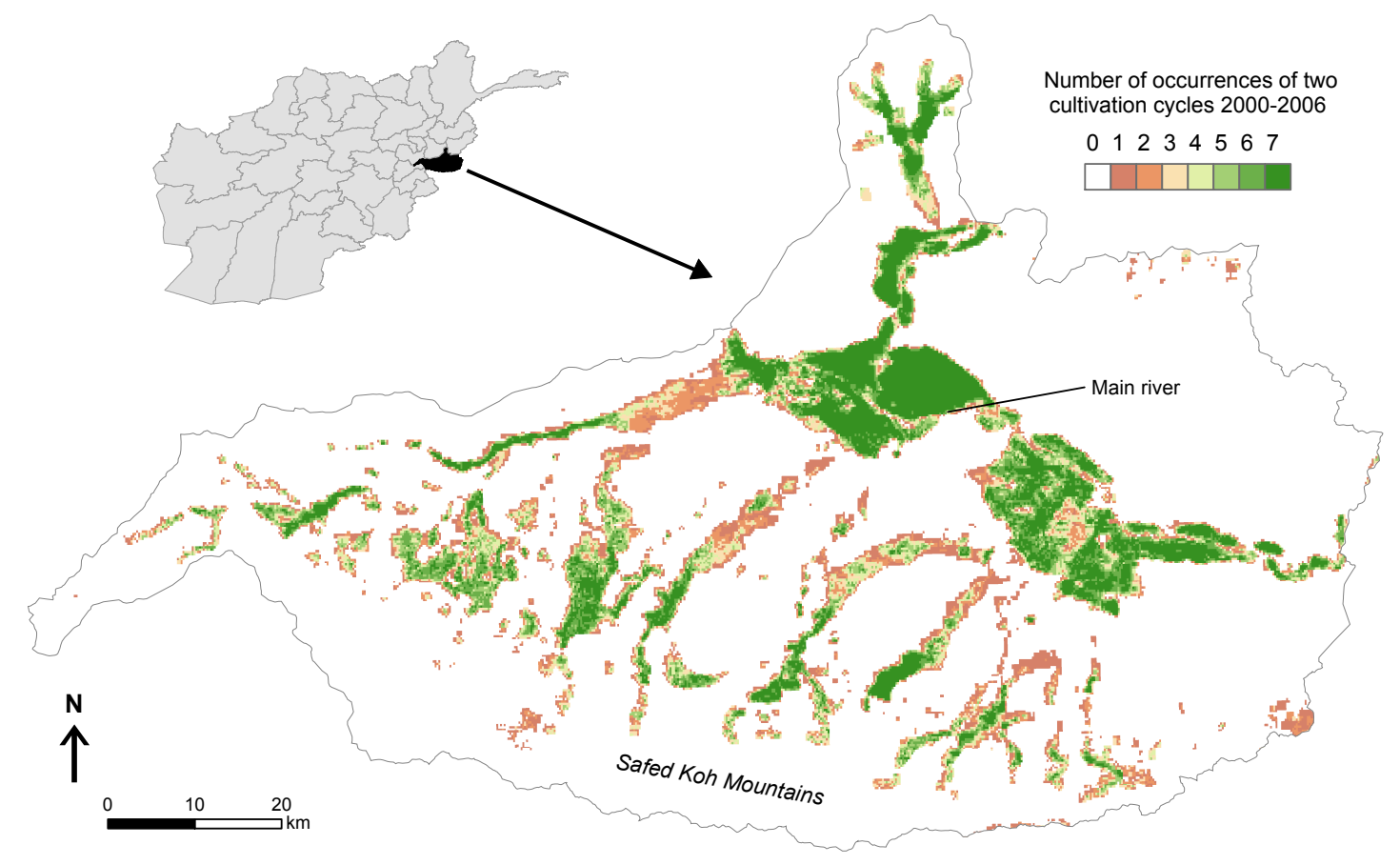

Figure 12: Reliability of double cropping in Nangarhar Province. 

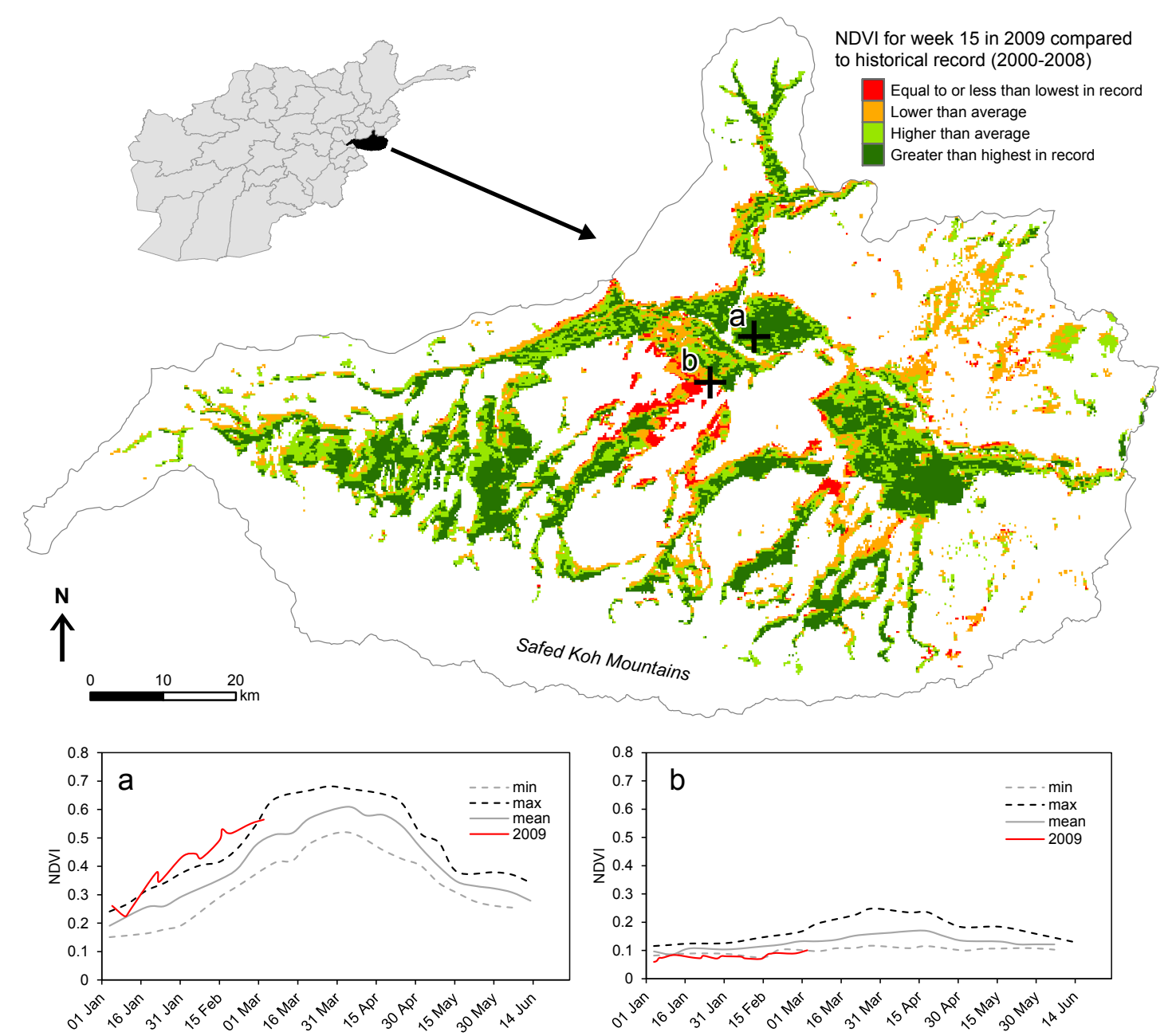

Figure 13: Drought status map for week 15 (2009) in Nangarhar Province and profiles showing the 2009 vegetation development in relation to the historical minimum, maximum and mean NDVI for the period 2000-2008 at locations a and b. 


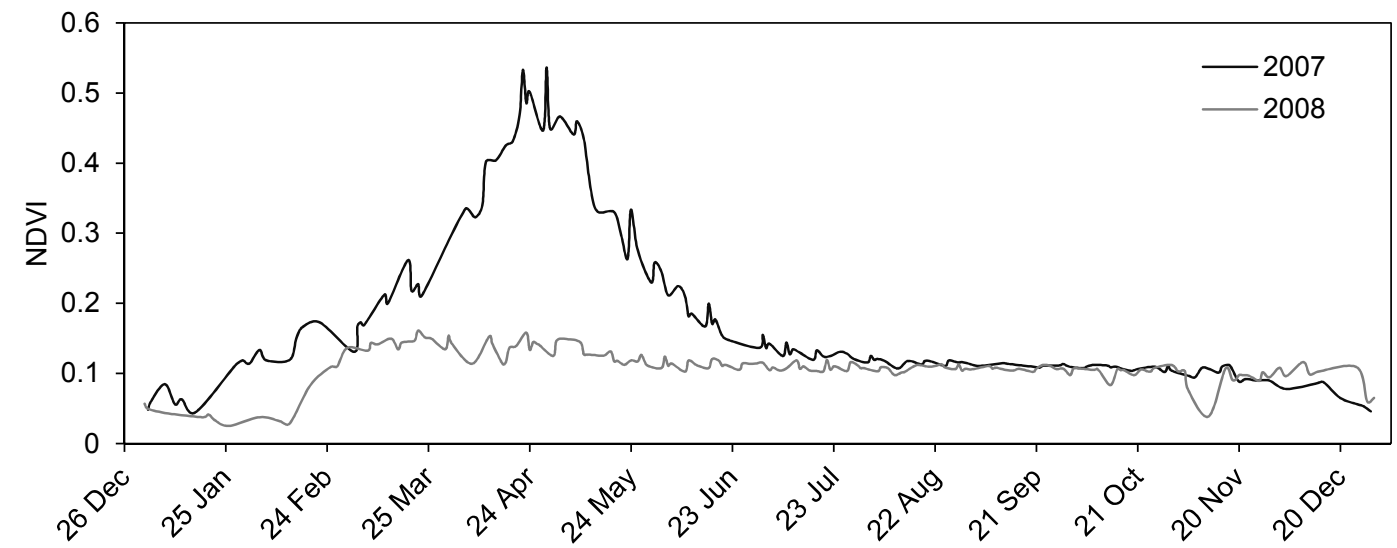

(a)

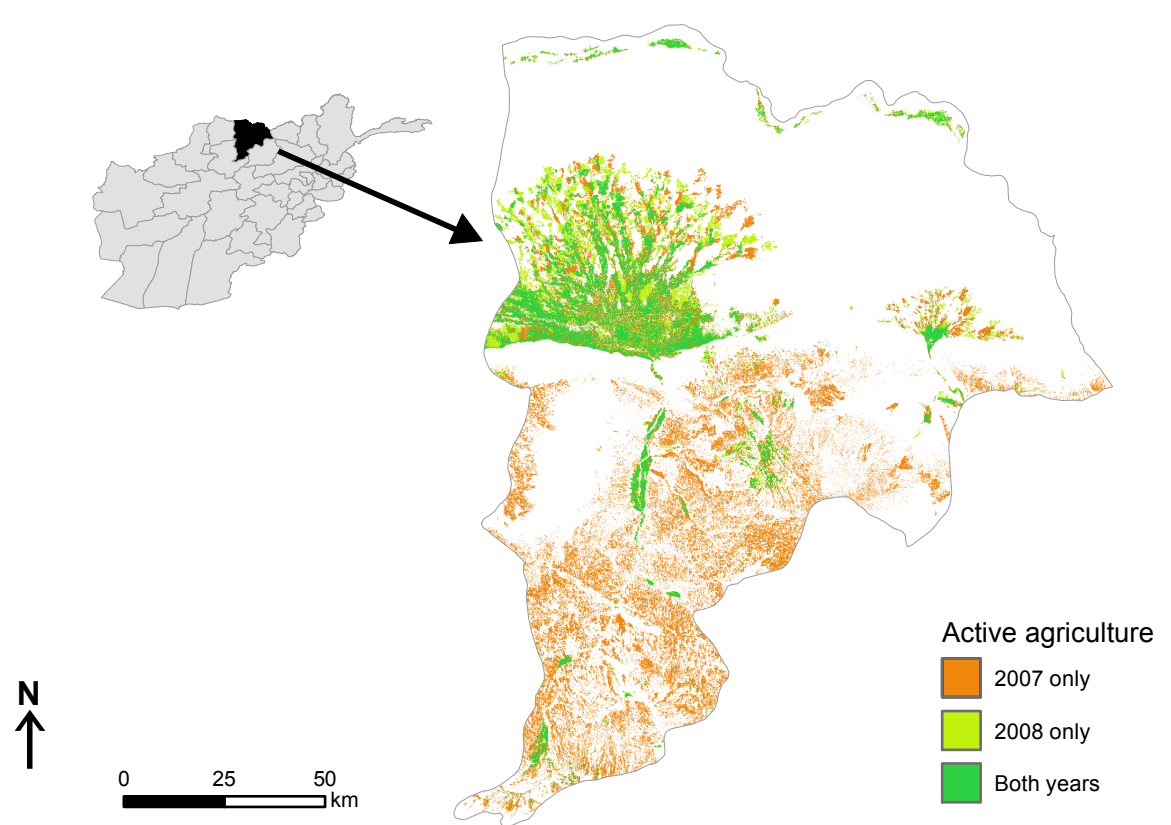

(b)

Figure 14: Typical MODIS NDVI vegetation profile from dry-land area in Sholgara District, Balkh Province (a), and area of agricultural land under production for Balkh Province in 2007 and 2008 (b). 


\section{Conclusions}

MODIS NDVI profiles were part of an operational system supporting cultivation surveys between 2005-2009 for the main opium producing provinces in Afghanistan. Despite the coarse spatial resolution of MODIS relative to the field sizes in Afghanistan, profiles are sensitive to phenological changes as the growth cycles of the main first cycle crops are in phase. The peak of the first growth cycle was found to be coincident with the flowering period for poppy crops and was used to assess the variation in timing induced by latitude and topography across Afghanistan. Profiles improved the accuracy of cultivation estimates by optimising the collection of VHR imagery for maximum interpretability of opium poppy from surrounding crops at sample locations. They also informed the selection of interpretation keys for crop growth stage within VHR images acquired outside of their planned collection windows because of cloud, improving interpretation.

The variation in height and number of peaks in the NDVI profile reflects the change in the productivity at any location between years. Historical data provided information on the reliability of cropping cycles and were used to investigate anecdotal claims of environmental impacts on the development of crops. Reports of crop damage caused by frost and disease were investigated and, once verified, used to estimate the spatial extent of the phenomenon.

Profiles are sensitive to localised variation caused by changes in land management and environmental factors such as water availability. Management zones were identified between adjacent groups of fields by their distinct profile shapes. Profiles were used to investigate the rotation of agricultural land and the development of newly exploited agricultural areas.

Visual interpretation of profiles found diagnostic features that correspond to certain crop mixes, especially those containing tree crops and vines. Further investigation is needed into the potential for automatic extraction of sub-pixel crop types using the shape characteristics of the profiles. Characterising the sub-pixel crop mix would improve the monitoring of phenology for specific crops and has potential for investigating yield variation over wide areas.

Mapping generated from the complete coverage MODIS NDVI database provided policy makers with detailed information on the quality and distribution of agricultural land. Specialised map products were produced for characterising the reliability of double cropping as an indicator of agricultural production levels on a country-wide basis. They were used for the targeting of counter-narcotics activities, such as crop eradication, and for evaluating the suitability of areas for providing farmers with alternatives to opium poppy cultivation.

MODIS imagery was processed in near-real time - images normally available for download from the NASA LAADS within 2 days of collection - allowing the geo-database of NDVI images to be kept up-to-date during the growing season. This enabled monitoring of vegetation green-up following snowmelt early in the crop growth cycle. The evolution of the current year's profile in relation to historical profile data provided: early warning of changes in the timing of opium crops compared with previous years; potential drought in irrigated areas; and the presence of vegetation in highly variable dry-land areas. Further investigation into the variation in production using a Vegetation Productivity Indicator (VPI), used by Sannier et al. (1998), is now possible given the length of the historical MODIS record.

Time-series NDVI profiles are a powerful tool for detailed vegetation monitoring. MODIS provides low cost, near real-time data over large geographical areas at the frequency required for capturing changes in crop development and land-use. This work 
demonstrates that MODIS $250 \mathrm{~m}$ NDVI profiles are sensitive to changes in crop phenology and management at the scale of the agricultural systems in Afghanistan. They are not limited to regional studies of natural systems or large-scale agriculture - where the field sizes are greater than the sensor resolution - and can be used operationally in nearreal time for monitoring localised variations in agricultural systems over large areas. This work also suggests different sub-pixel crop mixes could exhibit distinct NDVI profiles, enabling the approach to be used in other agricultural systems. There is great potential for applying these techniques in other geographical regions as MODIS data is provided free at the point of delivery, is global in coverage and has well-developed software tools. Profiles provide a low cost method for monitoring the variation in annual and inter-annual vegetation development for investigating changes in agricultural practices and land use, especially in fragile agricultural systems.

\section{Acknowledgements}

The authors would like to thank the UNODC and Ministry of Counter Narcotics, Government of Afghanistan, for making available the photo evidence and the UK Government for sponsoring the research. The MODIS data used in this study were acquired as part of NASA's Earth-Sun System Division and archived and distributed by the MODIS Adaptive Processing System (MODAPS).

\section{References}

Becker-Reshef, I., Vermote, E., Lindeman, M. and Justice, C., 2010, A generalized regression-based model for forecasting winter wheat yields in Kansas and Ukraine using MODIS data. Remote Sensing of Environment, 114(6), pp. 1312-1323. URL http: //dx.doi.org/10.1016/j.rse.2010.01.010

Goward, S.N., Markham, B., Dye, D.G., Dulaney, W. and Yang, J., 1991, Normalized difference vegetation index measurements from the advanced very high resolution radiometer. Remote Sensing of Environment, 35(2-3), pp. 257-277. URL http://dx. doi . org/10.1016/0034-4257(91) 90017-Z

Grodecki, J. and Dial, G., 2001, IKONOS Geometric Accuracy, in Proceedings of Joint Workshop of ISPRS Working Groups I/2, I/5 and IV/7 on High Resolution Mapping from Space 2001, pp. 19-21.

Hmimina, G., Dufrêne, E., Pontailler, J.Y., Delpierre, N., Aubinet, M., Caquet, B., de Grandcourt, A., Burban, B., Flechard, C., Granier, A., Gross, P., Heinesch, B., Longdoz, B., Moureaux, C., Ourcival, J.M., Rambal, S., Saint André, L. and Soudani, K., 2013, Evaluation of the potential of MODIS satellite data to predict vegetation phenology in different biomes: An investigation using ground-based NDVI measurements. Remote Sensing of Environment, 132(0), pp. 145-158. URL http://dx . doi .org/10 . 1016/ j.rse.2013.01.010

Huang, C., Townshend, J.R.G., Liang, S., Kalluri, S.N.V. and DeFries, R.S., 2002, Impact of sensor's point spread function on land cover characterization: assessment and deconvolution. Remote Sensing of Environment, 80, pp. 203-212. URL http://dx . doi .org/ 10.1016/S0034-4257(01)00298-X 
Huete, A., Didan, K., Miura, T., Rodriguez, E.P., Gao, X. and Ferreira, L.G., 2002, Overview of the radiometric and biophysical performance of the MODIS vegetation indices. Remote Sensing of Environment, 83(1-2), pp. 195-213. URL http://dx . doi .org/ 10.1016/S0034-4257(02) 00096-2

Justice, C.O., Townshend, J.R.G., Holben, B.N. and Tucker, C.J., 1985, Analysis of the phenology of global vegetation using meteorological satellite data. International Journal of Remote Sensing, 6(8), pp. 1271-1318. URL http: //www . informaworld.com/10.1080/ 01431168508948281

Sannier, C.A.D., Taylor, J.C., Du Plessis, W. and Campbell, K., 1998, Real-time vegetation monitoring with NOAA-AVHRR in Southern Africa for wildlife management and food security assessment. International Journal of Remote Sensing, 19(4), pp. 621-639. URL http://dx.doi.org/10.1080/014311698215892

Sannier, C.A.D., TAYlor, J.C. and Plessis, W.D., 2002, Real-time monitoring of vegetation biomass with NOAA-AVHRR in Etosha National Park, Namibia, for fire risk assessment. International Journal of Remote Sensing, 23(1), pp. 71-89. URL http://dx . doi . org/10.1080/01431160010006863

Taylor, J.C., Waine, T.W., Juniper, G.R., Simms, D.M. and Brewer, T.R., 2010, Survey and monitoring of opium poppy and wheat in Afghanistan: 2003-2009. Remote Sensing Letters, 1(3), pp. 179-185. URL http://www . informaworld.com/10.1080/ 01431161003713028

TuCKer, C.J., 1979, Red and photographic infrared linear combinations for monitoring vegetation. Remote Sensing of Environment, 8(2), pp. 127-150. URL http: //dx . doi . org/ 10.1016/0034-4257 (79)90013-0

UNODC, 2005, Afghanistan Opium Survey 2005, United National Office on Drugs and Crime, Vienna. URL https://www.unodc.org/documents/crop-monitoring/ Afghanistan/afg_survey_2005.pdf

van Leeuwen, W.J.D., OrR, B.J., Marsh, S.E. and Herrmann, S.M., 2006, Multi-sensor NDVI data continuity: Uncertainties and implications for vegetation monitoring applications. Remote Sensing of Environment, 100(1), pp. 67-81. URL http://dx . doi .org/ $10.1016 / j . r s e .2005 \cdot 10.002$

Victoria, D.D.C., da Paz, A.R., Coutinho, A.C., Kastens, J. and Brown, J.C., 2012, Cropland area estimates using Modis NDVI time series in the state of Mato Grosso, Brazil. Pesquisa Agropecuária Brasileira, 47(9), pp. 1270-1278. URL http://www.scielo.br/ $\mathrm{pdf} / \mathrm{pab} / \mathrm{v} 47 \mathrm{n} 9 / 12 . \mathrm{pdf}$

Viovy, N., Arino, O. and Belward, A.S., 1992, The Best Index Slope Extraction (BISE): A method for reducing noise in NDVI time-series. International Journal of Remote Sensing, 13(8), pp. 1585-1590. URL http://dx.doi.org/10.1080/01431169208904212

WARDLOW, B.D. and EgBert, S.L., 2008, Large-area crop mapping using time-series MODIS $250 \mathrm{~m}$ NDVI data: An assessment for the U.S. Central Great Plains. Remote Sensing of Environment, 112(3), pp. 1096-1116. URL http: //www. scopus. com/inward/record.url? eid $=2-$ s2 . 0-39749173163\&partner ID $=40 \& \mathrm{md} 5=5 \mathrm{e} 8 \mathrm{ef} 6 \mathrm{~b} 3 \mathrm{a} 6 \mathrm{acc} 1 \mathrm{f} 8 \mathrm{f} 33975 \mathrm{e} 92 \mathrm{db} 136 \mathrm{~cd}$ 
Wardlow, B.D., Kastens, J.H. and Egbert, S.L., 2006, Using USDA crop progress data for the evaluation of greenup onset date calculated from MODIS 250meter data. Photogrammetric Engineering and Remote Sensing, 72(11), pp. 1225-1234. URL http://www.asprs.org/a/publications/pers/2006journal/november/2006_ nov_1225-1234.pdf

Wolfe, R.E., Nishihama, M., Fleig, A.J., Kuyper, J.A., Roy, D.P., Storey, J.C. and Patt, F.S., 2002, Achieving sub-pixel geolocation accuracy in support of MODIS land science. Remote Sensing of Environment, 83(1), pp. 31-49. URL http://dx.doi.org/10.1016/ S0034-4257(02) 00085-8 